\title{
National Alliance for Photonics Education in Manufacturing: training in the application of photonics to enhance national manufacturing
}

Susan Anderson, Janice Gaines Walker

Susan A. Anderson, Janice M. Gaines Walker, "National Alliance for Photonics Education in Manufacturing: training in the application of photonics to enhance national manufacturing," Proc. SPIE 2525, 1995 International Conference on Education in Optics, (13 October 1995); doi: $10.1117 / 12.224081$

SPIE Event: SPIE's 1995 International Symposium on Optical Science, Engineering, and Instrumentation, 1995, San Diego, CA, United States 
The National Alliance for Photonics Education in Manufacturing: training in the application of photonics to enhance national manufacturing

\author{
Susan A. Anderson and Janice M. Gaines \\ SPIE--The International Society for Optical Engineering \\ Bellingham, Washington 98225
}

\begin{abstract}
NAPEM--The National Alliance for Photonics Education in Manufacturing is delivering photonics-based courses in four major manufacturing sectors: semiconductor manufacturing, laser materials processing, durable goods manufacturing, and dual-use manufacturing and end-to-end system testing. NAPEM's mission is to enhance industry competitiveness through providing practical continuing education programs on applying technology in manufacturing processes. Funded through a matching Technology Reinvestment Project (TRP) grant, NAPEM's unique approach unites the strengths of a professional photonics society, university educators, and industry training and human resources personnel in designing, assessing, implementing, and evaluating these innovative programs.
\end{abstract}

This paper will outline the NAPEM program, to date, from SPIE--The International Society for Optical Engineering's administrative perspective. It will identify successful models and lessons learned in program development, delivery and evaluation, and specify recommendations to assist others addressing similar educational issues in training an engineering workforce for the 21 st century.

Key Words: continuing education for industry, photonics education, training, educational alliance, continuing education for technology and manufacturing

\title{
2. INTRODUCTION
}

NAPEM was formed to address the need at the heart of the Clinton Administration's TRP program: to promote and develop national industrial capabilities that provide the most advanced and affordable military systems and the most globally competitive commercial products. This need was identified based on the U.S.'s declining global competitiveness in the commercial sector. Photonics* has been identified as a means to this end of improving our national capability: it is a rapidly evolving, enabling technology in defense and commercial industries, including a variety of manufacturing processes, and the U.S. Government has made considerable prior (and ongoing) investment in photonics R\&D and in its application to defense system needs.

NAPEM chose four manufacturing areas to focus on, based partly on the regional emphasis and expertise of each of the academic partners, and partly on the original vision of the project which identified various important manufacturing processes to target. Following is the background which led to the award and implementation of the grant and project.

*To clarify for this paper's purposes, NAPEM defines the term "photonics" as a broadly encompassing term to refer to technologies, techniques, devices, instruments and systems that generate, modify, or utilize electromagnetic energy in the wavelength range form $\mathrm{x}$-ray $(\sim 0.1 \mathrm{um})$ to far infrared $(\sim 10 \mathrm{um})$. 


\section{BODY}

\section{1 History: Conception of NAPEM and Grant Proposal Preparation}

\section{April 1993}

The seed for NAPEM was planted when staff from SPIE and Center for Research and Education in Optics and Lasers/Univ. of Central Florida attended a TRP overview meeting in Orlando, Florida, and as a result discussed a concept for educational programs which could complement the goals of the TRP. This concept was endorsed by SPIE's leadership, and as a result, Terry Montonye, SPIE's Senior Staff Technical Director, drafted an outline for a series of course programs geared toward the application of photonics in manufacturing processes in five or six regions around the country. Several industry representatives at Boeing, UTRC, and elsewhere reviewed and gave input to the plan. Potential alliance members were identified and solicited for their willingness to participate. The result was a collaborative grant writing effort with four academic partners (Industrial Technology Institute/Ann Arbor, CREOL/UCF, University of Connecticut, and University of Texas at Austin) who chose to commit to the project.

CREOL was chosen as the PI and contractor. SPIE coordinated the grant-writing effort and took on the role as administrator.

$\underline{\text { July } 1993}$

As part of finalizing the grant proposal, each Alliance member coordinated letters of support from industry and their local state governments. SPIE coordinated all text input for the proposal and then passed it to M.J. Soileau and staff at CREOL, who finalized the budget information and submitted the entire proposal on July 26th of 1993. The proposal requested funds of $\$ 1,315,342$ for a 36 -month program. The proposal consisted of cash contributions of $\$ 561$, tuition of $\$ 603 \mathrm{k}$, in kind contributions of $\$ 1,446 \mathrm{k}$, and $\$ 151 \mathrm{k}$ from Enterprise Florida.

\section{$\underline{\text { December } 1993}$}

SPIE was notified of the grant award in the amount of $\$ 1,200,000$ for the full 36 months. Al Harvey of NSF was named as the grant monitor.

\section{January 1994}

The NAPEM Alliance Board met for the first time to project a schedule and plan for initial phases of the project. Following this, several of the Alliance members identified and hired staff to support the effort at their facility.

\section{April 1994}

The first Curriculum Advisory Board (CAB) meeting was held in Austin, Texas, to identify potential courses and a viable program structure for the semiconductor manufacturing series. Although grant funding was not yet in place, Alliance members worked in good faith to establish preliminary groundwork for each of the NAPEM programs.

\section{October 1994}

The first series of NAPEM courses was launched in Austin. With funding finally in place, the other three Alliance partners preceded to identify $\mathrm{CAB}$ members and curriculum topics.

\subsection{Specifics of Alliance Partners and Structure}

NAPEM is made up of the following five partners and their PIs and key staff:

$\begin{array}{llll}\text { Site } & \underline{\text { PI }} & \underline{\text { Key staff }} & \text { Program Topic } \\ \text { SPIE } & \text { Janice Gaines } & \begin{array}{l}\text { Susan Anderson } \\ \text { Scott Walker }\end{array} & \begin{array}{l}\text { Administration } \\ \text { Promotion }\end{array}\end{array}$




\begin{tabular}{|c|c|c|c|}
\hline & & Terry Montonye & Technical \\
\hline $\begin{array}{l}\text { CREOLUniv. } \\
\text { of Central Florida }\end{array}$ & M.J. Soileau & J. J. Kim & $\begin{array}{l}\text { Dual-use manufacturing } \\
\text { End-to-end system testing }\end{array}$ \\
\hline Univ. of Texas at Austin & Ray Chen & Meg Karakekes & $\begin{array}{l}\text { Semiconductor } \\
\text { manufacturing }\end{array}$ \\
\hline Univ. of Connecticut & $\begin{array}{l}\text { Chandra } \\
\text { Roychoudhuri }\end{array}$ & Tariq Manzur & Laser materials processing \\
\hline $\begin{array}{l}\text { Industrial Technology } \\
\text { Institute }\end{array}$ & Kevin Harding & & Durable goods manufacturing \\
\hline
\end{tabular}

The management structure of the Alliance is a follows:

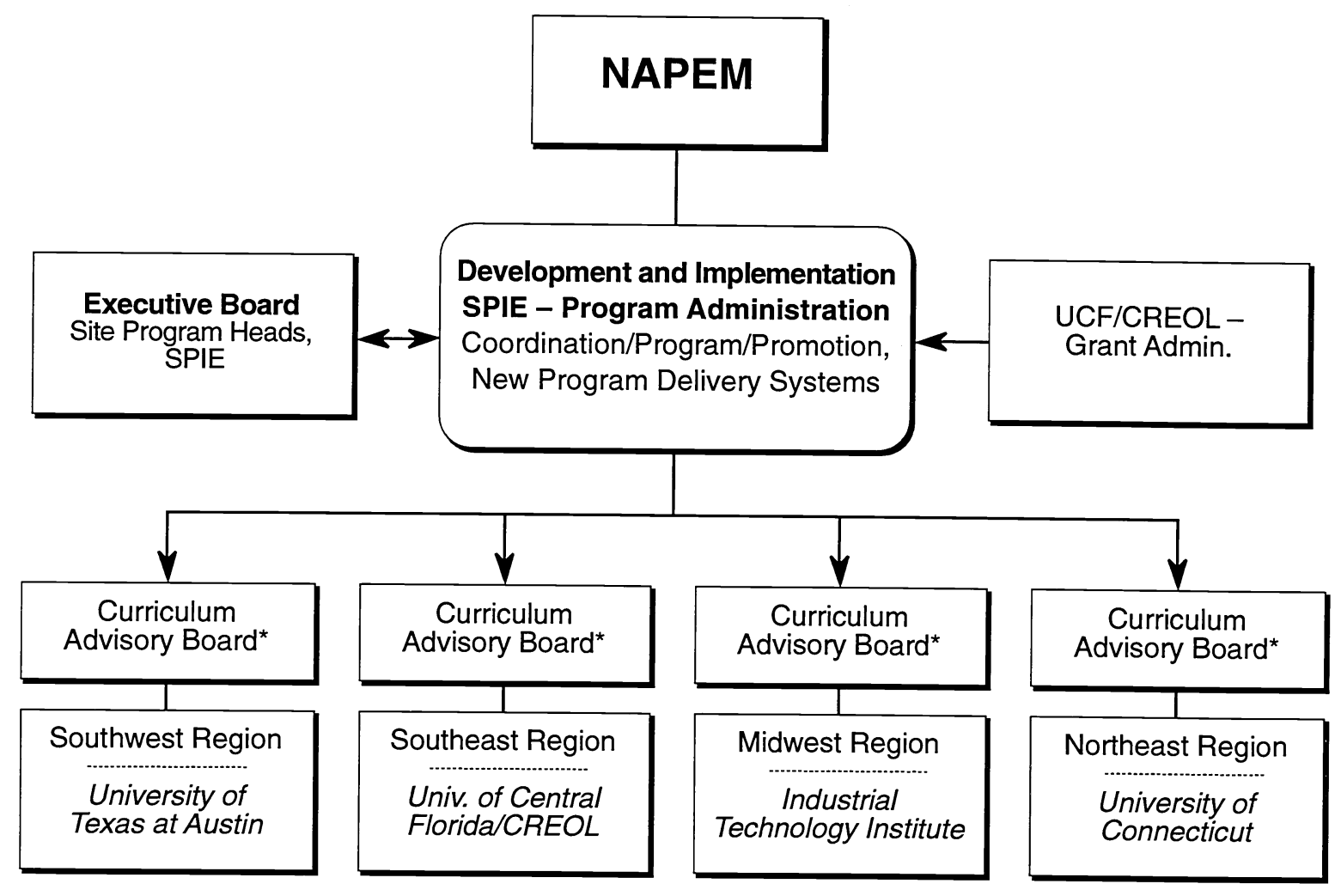

*Industry representatives, Alliance member Pls, Key staff and faculty 
As Alliance members formed their CABs and identified additional staff resources, it became more clear what their strengths were and what their specific roles and responsibilities would encompass. For example, each of the academic Alliance member brings highly experienced faculty to the project, but lacks experience in continuing education programs that specifically serve their established community of practicing engineers. SPIE has experience running successful continuing education programs, has an extensive database of individuals working in photonics, and has experience in company "outreach" (marketing visits to key company managers), but lacks extensive in-depth knowledge of the companies NAPEM was targeted to serve. The technical approach and management structure of the original NAPEM proposal articulated a disciplined method for enhancing each of these weaknesses by fostering industry/academic/society partnership on program development, delivery, and evaluation. The success and evolution of these partnerships are intended to create ongoing relationships between Alliance members and the companies they serve through the NAPEM program.

\subsection{SPIE's Role as NAPEM Administrator}

As mentioned above, this paper is written from SPIE's perspective as the administrator of NAPEM. The role that SPIE served in launching and now serves in supporting the Alliance is to partner with each academic member in developing, promoting, and delivering programs.

\subsubsection{Initial program development elements for each site included:}

- establishing the Curriculum Advisory Board (CAB) consisting of participating faculty from each member institution, regional industry representatives, key SPIE staff, and appointed experts;

- local industry surveys and promotions for each course series to alert potential industry participants to the training program development effort and to solicit input for course curriculum and scheduling elements;

- development of course curricula and identification of instructors;

- regularly held CAB meetings to refine content and advise on program scheduling to maximize attendance.

- SPIE worked with alliance members to find certification options and determine Continuing Education Unit

(CEU) criteria to enhance the value of courses to participants professional development.

\subsubsection{Challenges and lessons learned during program development phase included:}

\section{Identifying and Garnering Industry Support}

Gathering local industry representatives to serve on the CABs for the semiconductor and durable goods manufacturing programs was relatively "easy." Once CAB participants understood the partnering aspect and their ability to influence course curriculum and delivery elements, there was greater enthusiasm and support for the process. It is SPIE's assessment that those Alliance members who had previously established strong industry relationships, or who were able to quickly identify and cultivate key contacts within regional companies, were more successful with this phase. Securing industry support takes concerted time and numerous calls and visits to solidify affinity. A simple letter to a key manager with no follow up is a certain ticket to failure.

\section{Finding and Hiring the Right Staff Support}

UTA was fortunate to identify and hire a PhD candidate, Meg Karekekes, with experience working in semiconductor companies as a training and development coordinator. Her role with the UTA program became one of:

- identifying company human resources and training personnel to both serve on the CAB and help promote the program within their companies;

- identifying and implementing the third-level evaluation process; 
- assisting SPIE in telemarketing and arranging company visits with key industry personnel;

- providing advice on program scheduling issues as they relate to the semiconductor industry.

To date it is SPIE staff's opinion that this kind of support has strongly influenced the success of this UTA program and provided valuable evaluation models for the rest of the Alliance partners to emulate. It is imperative to have someone knowledgeable of the regional industry training infrastructure as part of the program team.

\section{Offering a Credential of Completion}

A certificate of completion for "Semiconductor Manufacturing Course series from Univ. of Texas at Austin University, College of Engineering" was jointly developed by SPIE, Dr. Ray Chen of UTA, and the UTA College of Engineering Continuing Education Director, Michael Jackson. This certificate recognized the university-equivalent quality of the three distinct sets of courses, and their completion and evaluation by the student. CEUs were also offered for completion of individual courses. While the certification program was accessed by only two-percent of the students, the CEUs were requested by thirty-one percent of NAPEM attendees.

The lesson learned here was that the certification program was not valued as highly for one or more of several reasons: the courses packaged for the three certification series were not appropriate, the university-equivalent credits were not valued, or the time away from work that it took to complete the series was not available to participants. The CEUs, however, were more popular, even if they did not weight as heavily in terms of academic value.

\section{Emphasize Real-World Curriculum}

SPIE Technical Staff were instrumentally involved in the semiconductor and optics manufacturing program curriculum development, in coordination with the CABs. SPIE drew on its extensive experience and database of short course subjects and course instructors, and provided straw man programs from which the CABs and alliance PIs could comment and refine. SPIE also recommended flexible scheduling elements including modular formats and alternative hours (weekends and evenings), drawing on experience and input from feedback from company members, and identified realworld industry experts to be instructors of various topics. It is our perspective that many of these elements contributed strongly to the success of these programs.

\section{Coordinating Multiple Partners}

Coordinating the four diverse Alliance member PIs and their staff and structuring their input and action was a significant and time-consuming challenge. Each organization has a unique operating style and culture, different budgeting and allocation constraints, different environmental factors, and different strengths and weaknesses in their ability to implement the program deliverables.

Strong organization and regular communication is essential to the administrative role. E-mail and phone communications greatly enhance the Alliance member's ability to communicate on a regular basis. Also, holding quarterly board meetings with NAPEM's NSF grant monitor helped focus and confirm the Alliance goals, and provided feedback for adjustment and emphasis of the program.

\section{Realities of a New Grant Program}

The TRP was a new grant program with underdeveloped policies, procedures, processes and guidelines for grant recipients. Although TRP emphasized partnering expressly for the goal of fostering new and strong relationships between government, industry, academia, and the professional societies, the process was in a pioneer stage. As a result, some of the goals for innovation and flexibility in the grant were in conflict with the inherent bureaucracies of working with the government and other large organizations.

\section{Know Your Target Population}

Feedback from NAPEM's experience in the Michigan region showed that progressive manufacturing organizations in durable goods are increasingly looking for technical fixes and solutions for problems that were in the past solved by the application of more workers. The method of introducing new technology solutions on the manufacturing floor tends to be 
through ad hoc research and implementation methods of company "champions of technology" (who often have the job title of quality engineer, control engineer, process engineer, or project engineer).

A lesson learned here was that these companies tended to be solution-driven, not technology-driven. NAPEM provides single-technology solutions to companies looking for multi-technology options which thus narrows our appeal to these quality, control, process, and project engineers. Had we know this in the beginning we would have altered drastically our promotion plan for this region, and conveying this understanding and concentrated on what photonics can do to solve specific manufacturing problems.

\subsection{NAPEM Program Promotion and Logistics}

\subsubsection{The following elements were part of each Alliance program promotion and on- site logistics:}

- marketing research conducted via telephone and paper survey methods;

- development of overall NAPEM promotional plan, including logo, letterhead, and press releases;

- development of specific promotion plans for each site;

- identification and contracting with facilities;

- obtaining curriculum feedback from $\mathrm{CAB}$ members;

- individual course administration: pricing, contracting with instructors, scheduling;

- promotional production and mailing: formatting, editing, printing, mail list and electronic promotion management, mailing;

- outreach efforts

- course registrations;

- on-site logistics and distribution of course materials and evaluations.

\subsubsection{Challenges and Lessons learned:}

\section{Network with The Right Industry Managers}

Key to the process of gaining feedback on topics and company interesting in sending participants to programs was the Alliance member institutions' standing in the community as well as making the right industry contacts. The reputation of the individual Alliance institutions played an important role in gaining entree as a respected educational provider.

Also, in the case of the semiconductor manufacturing series, it was also clear that even though brochures were mailed to companies at the engineering and manager level awareness of the program and commitment to participate were at extremely low levels until follow-up visits were made by SPIE and UTA. SPIE and UTA staff met with education/training personnel, engineering personnel, and human resources personnel from many major companies to discuss course topics and scheduling. It is SPIE's opinion that this influenced subsequent decisions allowing company personnel to attend. Internal distribution through accepted sources within companies is crucial to ensuring a wide participation from staff engineers.

\section{Talk the Talk}

Feedback from promotions of the ITI Michigan series of courses conveyed that promotional materials must be presented in companies' everyday language and with a solutions emphasis. Words that were too high-tech and which didn't describe what the course would do to enhance the employees' effectiveness in manufacturing processes missed the mark and did not attract course attendees.

\section{Choose Your Partners Well}

By partnering with organizations and other societies that have recognized and respected reputations for providing services 
to the target population, we enhanced local acceptance of semiconductor and durable goods NAPEM programs. It is our conclusion that acceptance and participation of leading companies in each manufacturing sector will lead to wider participation by personnel from suppliers of those manufacturers.

Also, in the case of the durable goods series, possibly collocating some courses and coordinating promotions with broadbased or solutions applications events sponsored by major players in the field will likely leverage exposure to larger audiences of in-house technology "champions" in attendance looking for solutions. We are experimenting with this aspect as this paper is written with the Michigan series.

\section{Meet Your Students' Needs}

Attendance in the programs we've held to date appears to be inversely proportionate to the distance away from the event. Feedback from series participants and company managers to date is that distance education opportunities would be popular. Programs located in major centers of industry seemed to draw the highest attendance per course, but NAPEM plans to provide distance learning opportunities to satisfy the needs of those who can not travel.

\subsection{Evaluation and Follow-up}

\subsubsection{Elements of this phase include:}

- collecting and processing course evaluations;

- continued follow-up dialogue with participating companies;

- providing support for third-level analysis to Alliance members;

- implementing feedback into each of the Alliance members' next program;

- reporting lessons learned back to all Alliance members, NSF grant monitor, and via required reports.

\subsubsection{Lessons learned:}

Ensure a high rate of return of your course evaluations

You can enhance evaluation return on-site through visits (brief reminders and collection) to course rooms, and asking instructors to reinforce the importance of and to allow time for filling out evaluation forms.

Reinforce dialogue with your industry partners (participants and CABs)

NAPEM partners must maintain contact with companies who attended the initial programs, refine programs based on their input, and continue to negotiate attendance packages to ensure appropriate content and high-levels of participation.

\section{Evaluation and follow-up takes time and a structured approach}

Only the UTA program employed a staff person for NAPEM with a background in third-level program evaluation. This activity takes a planned approach to asking the right questions and regular (three- and six-month) follow-up evaluations to identify if learned activity has been implemented in the workplace or has positively impacted their work. NSF has stated that this kind of information is critical to the entire project evaluation (i.e., how effective was this program?). Without established milestones and a timeline for this process it can be easily forgotten, as other pressing program scheduling issues prevail.

\section{Implement suggested program changes}

There are two issues here. One is lending credibility to your program by actually implementing requested improvements; and the other is that these improvements must be considered as helping to satisfy real needs and their implementation must result in a better program. As part of the second round of NAPEM program series we will evaluate suggested changes, develop a plan to implement those that are appropriate, and establish ways to measure their impact. 


\section{Report your findings}

With this particular program we are required to report findings and lessons learned to NSF specifically through regular reports, but as part of our obligation to our Alliance members (to help them learn from others' experiences) we also hold regular board meetings, and distribute via e-mail minutes, reports, and findings on a regular basis.

\section{OBSERVATIONS AND RECOMMENDATIONS}

We have so far in this paper identified specific recommendations on how to insure success within each specific phase of a program similar to this one. Now we will address overall observations and recommendations which we will ourselves implement as we carry out the remainder of this NAPEM program, and which we hope the reader also will find useful in carrying out similar activity.

\subsection{Observations}

There is a wide spectrum of approach in industry to implementing photonics as an enabling technology in manufacturing processes.

Educating U.S. manufacturing companies and personnel on the benefits of incorporating photonics as an enabling technology in their processes could be a whole project in itself. Some companies are more progressive than others. In the process of carrying out our outreach work we believe we successfully planted the seed with some companies, but with others did not.

For example, in Michigan in the durable goods industry we encountered companies who appeared to be significantly lagging behind in productivity and competitiveness due to lack of innovation and efficiency in manufacturing processes. One durable goods manufacturer had lost significant market share, was recently bought out by a non-U.S. investor, and continues to lose money. While touring their facility we identified at least seven areas where applications of photonics would significantly improve reliability, quality, and productivity. Company representatives were not receptive to our suggestions due to past negative experience with high technology. This response was in direct contrast to companies visited in the semiconductor and dual-use manufacturing areas.

Finding and serving displaced workers is not easy.

NAPEM programs in Austin were attended by several displaced workers, however, it is evident that the magnitude of work involved in locating, assessing needs, and serving these types of individuals in larger numbers could be a whole project in itself. How to transfer their former aerospace or related knowledge to new applications remains mostly elusive to this program to date.

The success story from the Austin program was one unemployed individual who participated then went on to find employment in the semiconductor field. This individual reported back during the follow-up process that the knowledge gained from the course series he took directly enhanced his hireability. Other unemployed participants commented that the exposure to the new technology in this program will help their employment opportunities.

The need for academia, industry, and the professional societies to partner in providing meaningful continuing education programs cannot be overemphasized.

The above statement was one of the stated objectives of the original TRP Manufacturing Education \& Training (MET) solicitation. As is evidenced in the literature, there have been many articles written about the need for the "ivory tower academics" to get their hands dirty in industry. It is our observation through the NAPEM process to date that SPIE adds a unique twist to a partnered approach:

- years of experience in quickly providing nontraditional continuing education programs

focusing on real-time and stated industry needs; 
- a global overview of emerging technology developments, needs, and experts to draw upon in providing appropriate courses;

- years of experience in fostering interaction among our members and customers from industry, academia, small business, and government.

We are filling a niche for engineers in the semiconductor manufacturing realm.

The NAPEM programs in Austin have led us to conclude:

- there is no universally accessible and all-encompassing established continuing education curriculum serving the semiconductor manufacturing industry's on-the-job training needs;

- in our discussions with the training and department managers of these companies it appeared that NAPEM is the only entity pursuing interactive partnership in the design and development of meaningful continuing education programs for this industry;

- many employed people commented on how the training increased their effectiveness and on-the-job performance.

This kind of message and the strength of it have not been clearly stated in any other NAPEM endeavor to date.

Spreading the alliance across four diverse topical and regional areas adds both positive and negative components. Based on our experience to date in administering this program, we have concluded that:

- Each Alliance member interprets the NAPEM vision differently as it relates to their program, and possesses different strengths in carrying out NAPEM goals. Part of our success to date is because the initial proposal identified a clear administrative structure which has been followed, for the most part.

- Learning from each Alliance member's experiences has been positive (time-saving, innovative, and errorreducing ideas and procedures have been regularly shared).

- Each Alliance member's resources are spread thin, limiting the ability to attain all goals equally.

- Each Alliance member has different programming challenges (both topical and scheduling), in-house procedures, terminology, and approaches which makes each program unique. Within these constraints establishing a largely repeatable model for each program is nearly impossible.

- Many alliance members have broadened their understanding and knowledge of industry issues through the process of developing, promoting, and gaining feedback on these programs.

The TRP, as a first-time major initiative, adds layers of complexity to the contract award, monitor, and report process.

Lack of established (tried and true) communications channels, procedures, and guidelines has contributed to

misunderstandings and confusion as to expectations and requirements during the process of interacting with TRP

administrators.

Professional societies should not have been disqualified as PIs.

SPIE's strength as an administrator would have been enhanced by also being the contract PI. Having the administrative coordination spread unnaturally between SPIE and CREOL (CREOL is the contract PI), increases the complexity of communications, reporting, and bureaucracy.

Funding commitment to the TRP/MET projects must not waiver once granted.

As governmental influences changed with the 1995 elections, suddenly project funding was not certain even after where were signed. This element of uncertainty led Alliance partners to reevaluate their ability and willingness to commit their matching resources to the project and caused delays in program development and implementation. 
SPIE's professional staff and standing in the community adds a unique contribution to this project. In addition to the strengths SPIE brings to this program mentioned in previous sections of this paper, SPIE 's professional staff has experience in motivating volunteers to action, and in continuing education curriculum development and other program design elements. Also, SPIE, as a noncommercial organization, is a non-threatening Alliance member and service provider. We believe these elements have contributed significantly to NAPEM's successes.

\subsection{Recommendations}

Course programs must be short in duration and near major industry centers.

In developing the original NAPEM concept, the length of courses programs was originally proposed to be two weeks. However, as industry played a larger development role, it was clear that shorter course lengths would be more widely supported.

As mentioned above, we also learned from the semiconductor manufacturing experience that attendance to programs is inversely proportionate to the distance away from the event, and that distance education opportunities will likely have a strong market as long as they are kept current with stated needs.

Speak your customer's language.

As mentioned above, manufacturers told us that it is essential that promotional educational materials and solicitation for participation be presented in their everyday language.

More alliances with other associations outside NAPEM will increase credibility, visibility.

Key contacts in companies are already participating in trade shows and industry activities sponsored by other familiar associations or organizations. We must take advantage of the promotional opportunities their lists and shows provide and enhance our program's credibility by gaining their endorsement.

\section{Emphasize hands-on activities.}

Hands-on activities are proven highly effective in learning retention, and feedback from NAPEM CABs has emphasis the need for greater hands-on training. The challenge for NAPEM is to find more opportunities for hands-on programs by locating facilities that can accommodate multiple students (more than five at a time) and who are nonproprietary.

Committing adequate time and resources.

We believe in the good this program is doing (evidenced in feedback from program attendees) but feel we could enhance its impact significantly with more resources.

For example, more resources would allow:

- increased follow-up with attendees to determine long term impact of programs;

- more indepth outreach to companies (time to ID and follow up with companies) to increase exposure and

participation;

- more time to identify displaced workers to increase exposure and participation;

- more time to educate manufacturing company personnel about photonics as an enabling technology;

- more comprehensive program-end analysis and conscientious-raising opportunities.

The sluggish state of the economy was one of the factors that initiated the TRP program. Current unemployment rates at five percent lead us to believe that this target population, who were one of the main focus groups in the beginning of the program, may be less in need of this type of retraining. The upturn in the economy also supports another NAPEM goal-the overall education aspect of making industry aware of photonics and its manufacturing applications will lead toward competitive advantages. 
Expand the program focus to include more than photonics.

Photonics is only a part of the technology solution package that can be implemented for any particular manufacturing problem. We found some companies to be looking for more broad-based solutions and wanting to shop in more than one technology area.

\section{SUMMARY}

This paper has outlined the steps, lessons learned, observations, and recommendations implemented and identified for a continuing education program for applying photonics to diverse manufacturing processes. In this paper we hope to accomplish three things:

1) Solidify our conclusions and understanding of the process and lessons learned for future program modification;

2) Report on the good that this program is doing;

3) Identify lessons learned for others launching similar programs so that challenges can be shared and success more easily assured.

We feel that NAPEM has been an extremely valuable and worthwhile experience for both SPIE and the program participants (including course attendees and other Alliance members). The goal is to bring NAPEM to a self-sustaining point by the time the TRP funding runs out in order to continue spreading the word about photonics.

At this point we would like to acknowledge all those who have helped make this program successful to date. We would also like to state here that the opinions expressed in this paper are solely those of the authors, and do not claim to represent the other NAPEM Alliance members, their staffs, the TRP or NSF monitors, program participants, or SPIE members. Finally, we apologize if we miss anyone in our acknowledgements--you know if you assisted us and we thank you.

\section{ACKNOWLEDGEMENTS}

SPIE Leadership: Ted Saito, Past President; David Casasent, Past President; 1994-1995 SPIE Education Committee members.

SPIE Staff: Terry Montonye, Sr. Staff Technical Director; Scott Walker, Sr. Staff Development Director; Jim Pearson, Executive Director; Jit Rai-Choudhuri, Technical Director; Elsie Heinrick, Deputy Director, Sharon Kirkpatrick, Accounting Manager; Education Services Department Staff.

SPIE Consultants: Doug Holmstrom, Cygnus Lasers; Rick Feinberg, Western Washington University.

CREOL/UCF: M.J. Soileau, Director; Jin Kim, Professor; Donna Wilson, Administrative Assistant; Thomas O’Neal, Business Manager, CREOL/Univ. of Central Florida.

UTA: Ray Chen, Professor; Meg Karekekes, Advanced Micro Devices and UTA PhD Candidate; Janna Oddie, Administrative Assistant.

ITI: Kevin Harding, Principal Scientist; Ray Vanderbok, Regional Manufacturing Representative.

UConn: Chandra Roychoudhuri, Director; Tariq Mazur, Program Manager; Richard Becherer, Delta Sciences.

NSF: Al Harvey, Program Director, National Science Foundation, TRP Grant Monitor. 


\section{REFERENCES}

Program Information Package for Defense Technology Conversion, Reinvestment, and Transition Assistance, ARPA, Technology Reinvestment Project, Arlington, VA, March 10, 1993.

Manufacturing News \& Dual-Use Technology, Falls Church, VA, June 1, 1995. 